\title{
Powder and Solvent for Solution for Injection/Infusion Dosage Form
}

National Cancer Institute

\section{Source}

National Cancer Institute. Powder and Solvent for Solution for Injection/Infusion Dosage

Form. NCI Thesaurus. Code C149800.

Sterile powder and sterile solvent intended for the preparation of a solution for injection/infusion by dissolving the powder in the solvent. 